\title{
ARQUITETURA E EVOLUÇÃO DEPOSICIONAL DA SUCESSÃO SEDIMENTAR PLEISTOCENO TARDIO-HOLOCENO (ÚLTIMOS 20 Ka) DA BAÍA DE SEPETIBA (RJ)
}

\author{
ARCHITECTURE AND DEPOSITIONAL EVOLUTION OF THE LATEST PLEISTOCENE- \\ HOLOCENE (LAST 2OKY) SEDIMENTARY SUCCESSION OF SEPETIBA BAY (RJ) \\ Antonio Tadeu dos REIS ${ }^{1}$, Guilherme AMENDOLA ${ }^{2}$, Tatiana Pinheiro DADALTO ${ }^{3}$, \\ Cleverson Guizan SILVA ${ }^{4}$, Raiane TARDIN POÇO ${ }^{5}$, Josefa Varela GUERRA ${ }^{1}$, Virginia \\ MARTINS $^{6}$, Renata Rebouças CARDIA ${ }^{1}$, Christian GORINI ${ }^{7}$, Marina RABINEAU ${ }^{8}$ \\ ${ }^{1}$ Faculdade de Oceanografia (FAOC), Universidade Estadual do Rio de Janeiro (UERJ). \\ E-mails: tadeu.reis@gmail.com; josie.guerra@gmail.com; rcr.renata@gmail.com \\ ${ }^{2}$ Pós-Graduação em Oceanografia (PPG-OCN/UERJ). E-mail: guilherme.amendola.s@gmail.com \\ ${ }^{3}$ Pós-Graduação em Dinâmica da Terra e dos Oceanos (DOT/UFF) e Instituto de Humanidades, Artes e Ciências, Universidade \\ Federal do Sul da Bahia (UFSB), Campus Sosígenes Costa (IHAC/CSC). E-mail: tpdadalto@ufsb.edu.br \\ ${ }^{4}$ Departamento de Geologia (LAGEMAR), Universidade Federal Fluminense (UFF). E-mail: cguizan@id.uff.br \\ ${ }^{5}$ Pós-Graduação em Dinâmica da Terra e dos Oceanos (DOT/UFF). E-mail: raytardin@gmail.com \\ ${ }^{6}$ Faculdade de Geologia (FGEL), Universidade Estadual do Rio de Janeiro (UERJ) e Universidade de Aveiro, GeoBioTec, \\ Departamento de Geociências, Campus de Santiago, 3810-193 Aveiro, Portugal. E-mail: virginia.martins@ua.pt \\ ${ }^{7}$ Institut des Sciences de la Terre de Paris (iSTeP), Sorbonne Université. E-mail: christian.gorini@upmc.fr \\ ${ }^{8}$ Institut Universitaire Européen de la Mer (IUEM), Université de Bretagne Occidentale (UBO). Domaines Océaniques (UMR 6538). \\ E-mail: marina.rabineau@univ-brest.fr

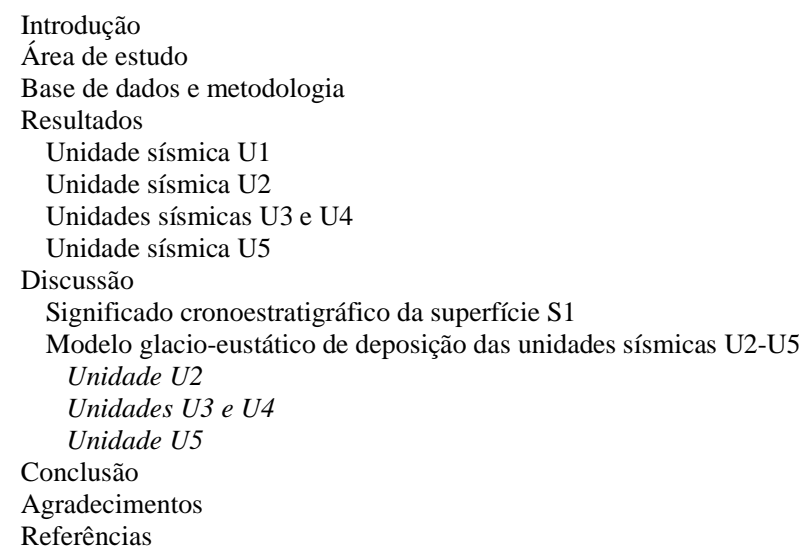

RESUMO - A baía de Sepetiba, localizada na costa oeste fluminense, consiste de um embaiamento onde predominam condições estuarinas com contato limitado ao oceano aberto, devido à presença da restinga da Marambaia - uma ilha-barreira de $\sim 40 \mathrm{~km}$ de comprimento. O presente estudo visa o detalhamento da evolução estratigráfica do preenchimento sedimentar da baía, baseado na análise de $\sim 800 \mathrm{~km}$ de linhas sísmicas de alta resolução, correlacionada a dados de datação de horizonte sísmico na plataforma continental $\left({ }^{14} \mathrm{C}\right.$ AMS $)$ e de estágios de evolução da restinga da Marambaia $\left({ }^{14} \mathrm{C}\right.$ AMS/LOE). A integração dos resultados revelou a existência das unidades U2-U5 - uma sucessão sedimentar transgressiva e de mar alto de até 30 m de espessura, que testemunha a implantação de um sistema estuarino aberto na região em direta conexão com o mar (deposição de U2), que evoluiu para condições estuarinas progressivamente mais isoladas (deposição das unidades U3 e U4) até atingir uma configuração de ambiente estuarino de baixa energia sem conexão direta com o mar (deposição da unidade U5), similar às condições do sistema deposicional atual. Os diferentes ambientes estuarinos, revelados pela fácies sísmicas das unidades U2-U5, estão diretamente correlacionados às diferentes fases de construção e/ou fechamento da restinga da Marambaia.

Palavras-chave: Deposição transgressiva; Paleosistema estuarino; Transgressão Pleistoceno Tardio-Holoceno.

\begin{abstract}
The Sepetiba Bay, located in the western coastal area of Rio de Janeiro state, consists of an embayment where estuarine conditions prevail, due to its limited contact to open ocean being isolated by a barrier island of $\sim 40 \mathrm{~km}$ extent - restinga da Marambaia. The present study aims at investigating the stratigrahic evolution of the bay's infilling units, based on seismic anlysis of $\sim 800 \mathrm{~km}$ of high-resolution reflection seismic profiles. Seismic analysis was coupled with previously dated horizon on the Rio de Janeiro continental shelf $\left({ }^{14} \mathrm{C}\right.$ AMS), as well as with recently-dated sedimentary evolutional stages of the Marambaia barrier island $\left({ }^{14} \mathrm{C}\right.$ AMS/OSL). Integration of all results revealed the existence of a transgressive-highstand sedimentary sucession (up to $30 \mathrm{~m}$ thick) composed of units U2-U5 which testifies the onset and evolution of estuarine conditions in the Sepetiba area: an open ocean estuarine system (deposition of unit U2) progressively envolved into more isolated estuarine conditions (depositions of units U3-U4), until attaining the configuration of a low energy estuarine environment no longer in direct connection with the open sea (deposition of Unit U5), related to the constructional phases of the Marambaia barrier island itself.

Keywords: Transgressive deposition; Paleoestuarine system; Latest Pleistocene-Holocene transgression.
\end{abstract}




\section{INTRODUÇÃO}

A baía de Sepetiba, situada na região costeira oeste do estado do Rio de Janeiro, consiste de um embaiamento com contato limitado com o oceano aberto, devido à construção sedimentar da restinga da Marambaia - uma ilha-barreira de cerca de $40 \mathrm{~km}$ de comprimento. O principal barreira (Figura 1).

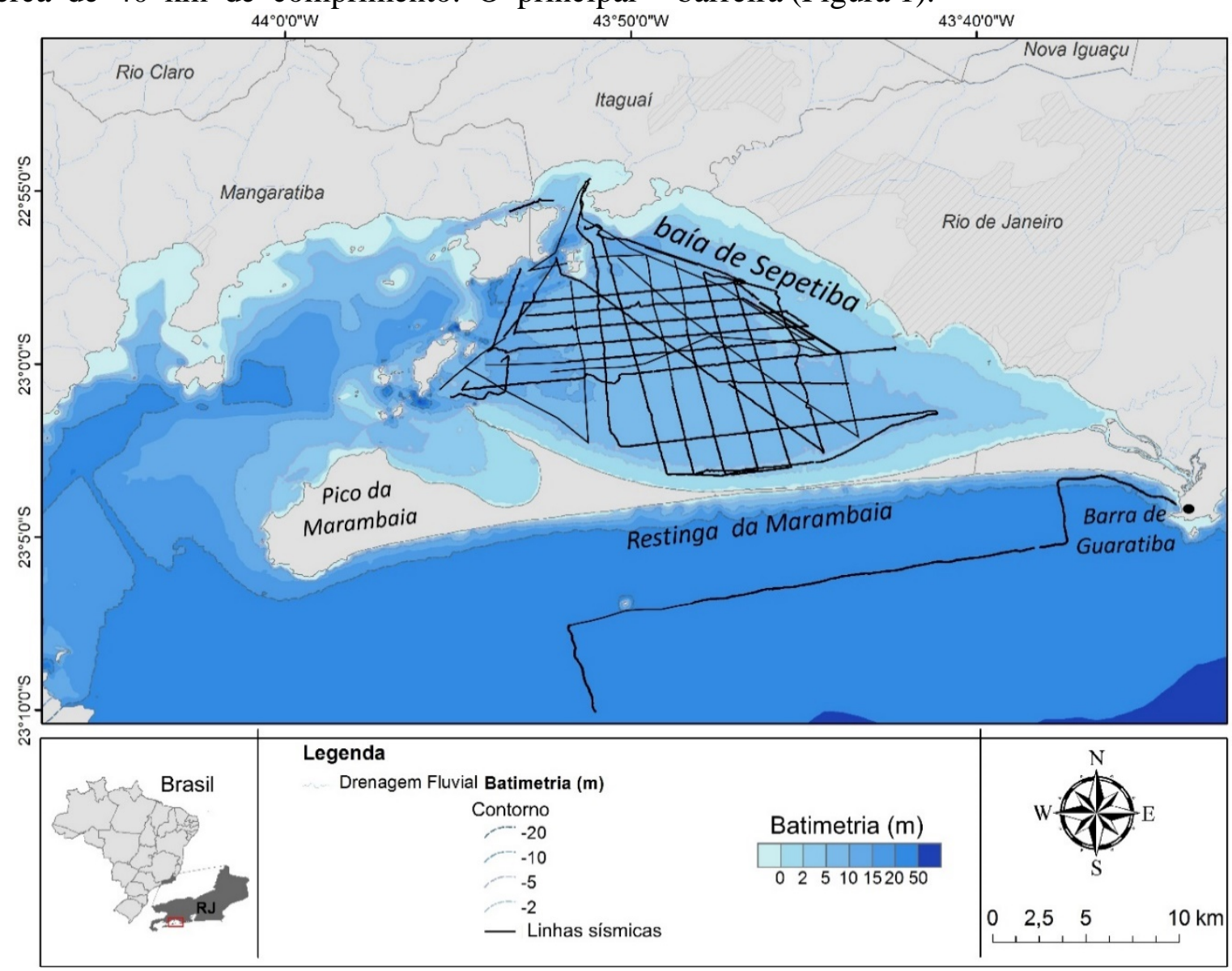

Figura 1. Localização da área de estudos - a baía de Sepetiba. Em linhas pretas o posicionamento das linhas sísmicas de alta resolução (fonte Boomer 100J de potência) utilizadas no presente estudo, adquiridas na baía de Sepetiba com uma fonte sísmica do tipo boomer de 100J.

Estudo realizado na plataforma continental interna-média, adjacente à baía, revelou a existência de fácies sísmicas que indicam a deposição de uma sucessão sedimentar de ambientes fluvio-estuarinos (na base) passando para estuarinos (no topo). Essa sucessão está depositada sobre uma superfície basal erosiva localizada a cerca de $30 \mathrm{~m}$ abaixo do fundo marinho atual (Friederichs et al., 2013). No entanto, estudos estratigráficos na escala de toda a baía de Sepetiba são relativamente escassos. Estudo realizado no interior da baía, com base em dados de ecobatimetria de subfundo (Singlebeam echo sounder) e uma datação próxima da restinga $\left({ }^{14} \mathrm{C}\right.$ AMS), propôs a existência de um preenchimento sedimentar holocênico, de espessura média de $\sim 5 \mathrm{~m}$, depositado diretamente

contato com o oceano se encontra na parte oeste da baía, fazendo com que a maior parte da baía, a leste, esteja isolada do mar aberto pela restinga da Marambaia, o que resultou na implantação de condições estuarinas no ambiente de retro-

$43^{\circ} 40^{\prime} \mathrm{O}^{\prime \prime} \mathrm{W}$ 
região foi submetida desde a última deglaciação, iniciada globalmente por volta de 20 ka A.P. (Bard et al., 1990). O estudo se baseia na análise de uma base de dados sísmicos de alta resolução coletada no interior da baía, que permite a penetração do sinal sísmico até cerca de 40-50 m de espessura sedimentar abaixo do fundo. Esse estudo é também o primeiro a contar com a correlação de informações de idade de refletor regional na plataforma fluminense (Poço, 2015) e de idades das principais fases de construção da restinga da Marambaia, recentemente disponibilizadas
(Dadalto, 2017). Os objetivos específicos do presente trabalho são: (i) identificar as principais unidades sísmicas de preenchimento da baía de Sepetiba e compreender seu significado paleoambiental no contexto da evolução paleogeográfica da baía; (ii) compreender como a região respondeu à transgressão pós-último máximo glacial (últimos 20ka); e (iii) correlacionar as características de fácies sísmicas das unidades identificadas no interior da baía de Sepetiba com as fases de desenvolvimento da restinga da Marambaia, recém definidas (Dadalto, 2017).

\section{ÁREA DE ESTUDO}

A baía de Sepetiba está situada na porção costeira oeste do estado do Rio de Janeiro abrangendo uma área de cerca de $300 \mathrm{~km}^{2}$, correspondente à porção oeste do chamado Gráben da Guanabara, parte do Sistema de Riftes Cenozoicos do Sudeste do Brasil (Zalán \& Oliveira, 2005; Figura 1).

Durante o Quaternário Superior (últimos 500 ka), a região de Sepetiba e a plataforma continental fluminense foram submetidas a regressões e transgressões marinhas: as regressões marinhas ocorreram em ciclos glacio-eustáticos de 100-120 ka de duração, durante os últimos 440500 ka, que ocasionaram significativa diminuição do nível de base ( \pm 120-140 m) através de lenta exposição da área durante ciclos glacio-eustáticos de 100 ka de duração; já durante as transgressões marinhas, o afogamento da região ocorreu rapidamente, durante ciclo de $\sim 20$ ka (Rabineau et al., 2006; Maia et al., 2010; Reis et al., 2013; Friederichs et al., 2013; Figura 2). Além disso, o estudo das oscilações eustáticas do Holoceno Tardio (últimos $\sim 7 \mathrm{ka}$ ) na região sudeste do Brasil revelou a ocorrência de situação de nível de mar acima do atual ( $\sim \mathrm{m})$, evidenciado por um nível de transgressão máxima ocorrido em 5.8 ka A.P. (Angulo et al., 2006) - curva aplicável à área de estudo..

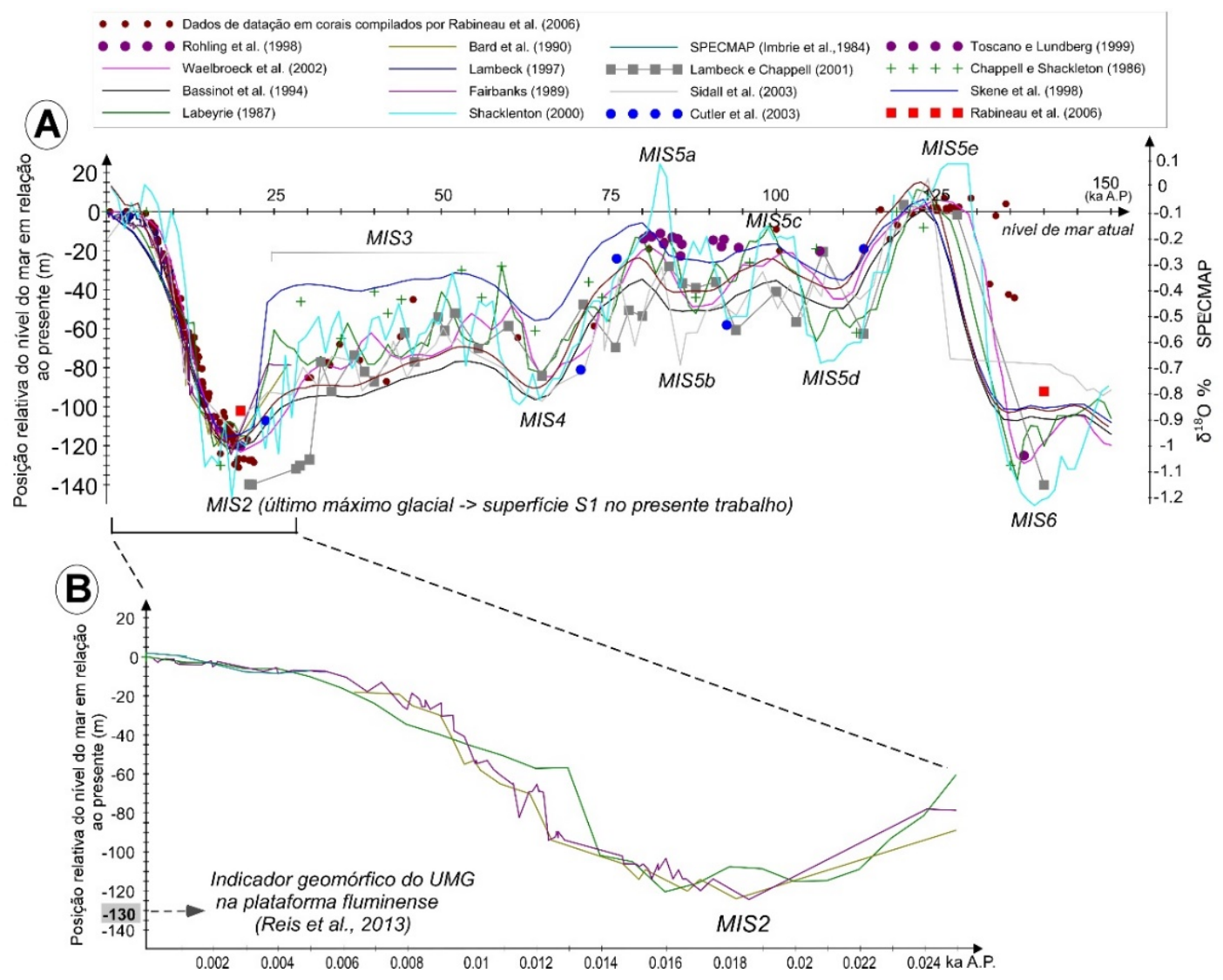

Figura 2. Envelope de curvas eustáticas baseada na razão isotópica $\delta^{18} \mathrm{O}$ e calibradas por evidências geológicas datadas globalmente pelos autores listados na legenda acima (modificado de Reis et al., 2013). UMG= Último Máximo Glacial. 
Uma investigação estratigráfica englobando maior espessura sedimentar (primeiros $300 \mathrm{~ms}=$ $240 \mathrm{~m}$ ) foi realizada na plataforma continental, através da análise de dados de sísmica de alta resolução (fonte sísmica sparker) e de dados cronoestratigráficos de poços de exploratórios (Maia et al., 2010). Os autores identificaram a existência de cinco sequências atribuídas ao Quaternário Superior (Sq1, Sq2, Sq3, Sq4, Sq5), separadas entre si por superfícies erosivas bastante irregulares, associadas a períodos de exposição lenta da plataforma continental nos últimos $\sim 500 \mathrm{ka}$, a exemplo do observado na plataforma do Golfo de Lion, França (Rabineau et al., 2006). Contudo, apenas as sequências Sq4 e Sq5 (depositadas nos últimos $\sim 130 \mathrm{ka}$ ) estão preservadas nas regiões de plataforma rasa e região costeira, enquanto as demais sequências (Sq1, Sq2 e Sq3) encontram-se preservadas somente nas porções da plataforma médiaexterna atuais (> $100 \mathrm{~m}$ de profundidade da lâmina d’água atual; Maia et al., 2010).

Ainda no contexto das implicações sedimentares das variações glacio-eustáticas na plataforma adjacente à baía de Sepetiba, área até 30-40 km de distância da costa, foi observado
(Friederichs et al., 2013): (i) o empilhamento de uma sucessão de fácies sísmicas indicativas da deposição de alternância de ambientes fluvioestuarinos - na base, para ambientes estuarinos, lagunares e marinhos rasos - no topo, compreendendo os primeiros $\sim 30 \mathrm{~m}$ de espessura sedimentar abaixo do fundo marinho. Essas unidades sísmicas foram interpretadas como resultantes do afogamento da plataforma continental durante a última deglaciação; (ii) uma rede de paleocanais presentes numa superfície erosiva basal da sucessão estratigráfica. Os paleocanais foram interpretados como vales fluviais incisos esculpidos durante a última regressão marinha global, ocorrida entre MIS5e-MIS2 (Figura 2). Estudo estratigráfico de detalhe foi também realizado na região da própria restinga da Marambaia, a partir da análise de dados geofísicos acoplados à datação de intervalos estratigráficos $\left({ }^{14} \mathrm{C}\right.$ e $\left.\mathrm{LOE}\right)$, permitindo a proposição de um primeiro modelo de correlação estratigráfica entre unidades deposicionais dos ambientes de plataforma rasa e da baía com as principais fases de construção da restinga da Marambaia (Dadalto, 2017).

\section{BASE DE DADOS E METODOLOGIA}

Esse trabalho dispõe de cerca de $800 \mathrm{~km}$ de linhas sísmicas de alta resolução, adquiridas durante missões oceanográficas realizadas entre setembro/2012 e janeiro/2013 (Figura 1). Os dados sísmicos foram adquiridos com um Sistema Sísmico Boomer AA301, da marca Applied Acoustics Engeneering Ltda, operado na potência de 100 Joules. A configuração de energia possibilitou a geração de sinais acústicos numa banda de frequência entre $\sim 2-5 \mathrm{kHz}$. Tais parâmetros de aquisição permitiram o imageamento sísmico dos estratos sedimentares até $\sim 50-60 \mathrm{~ms}$ abaixo do fundo, ou seja, o imageamento dos estratos sedimentares dos primeiros $\sim 40-50 \mathrm{~m}$ de espessura sedimentar abaixo do fundo marinho, considerando-se uma velocidade média intervalar de propagação do sinal acústico de $1600 \mathrm{~m} / \mathrm{s}$ - velocidade utilizada anteriormente na região (Friederichs et al., 2013).

Os dados sísmicos brutos foram processados com o auxílio do programa livre Seismic Unix (SU), através da aplicação de uma rotina de etapas de processamento que incluiu: o filtro mute, que tem como objetivo melhorar a delimitação do fundo marinho; o swell filter, utilizado para retirada do efeito indesejado das ondas do mar sobre a forma, continuidade e geometria dos refletores; e, finalmente, a aplicação de uma série de filtros passa-banda, usados para melhorar a razão sinal/ruído, a fim de permitir o imageamento de fácies e refletores sísmicos localizados a diferentes profundidades na sucessão sedimentar.

A interpretação dos perfis sísmicos foi realizada de acordo com os princípios gerais de Sismoestratigrafia (e.g., Mitchum et al., 1977) e da Estratigrafia de Sequências de Alta Resolução, sintetizada em Catuneanu (2006). Foram também utilizados estudos de caso de paleoambientes estuarinos e marinhos rasos, baseados em interpretação sísmica de alta resolução e em descrição de testemunhos de colunas sedimentares (e,g., Chaumillon et al., 2010; Seminack, \& Buynevich, 2013; Ho Bae et al., 2018). Esse método permitiu: (i) a identificação de unidades deposicionais e suas superfícies limitantes; (ii) a definição de fácies sísmicas internas das unidades, indicativas da implantação de diferentes ambientes deposicionais ao longo do tempo. 


\section{RESULTADOS}

A interpretação da base de dados sísmicos resultou na identificação de cinco unidades sísmicas: as unidades U1, U2, U3, U4 e U5 (Figura 3), limitadas por superfícies contínuas nos seus limites superior e basal (as superfícies S1 a S5). As unidades U1-U5 são lateralmente contínuas em toda a área de estudo e apresentam diferentes conjuntos de fácies sísmicas internas, indicando tratar-se de ambientes deposicionais com diferentes características oceanográficas (Tabela 1).

\section{Unidade sísmica U1}

A unidade sísmica U1, unidade mais basal, teve apenas o seu topo (a superfície S1) identificado nas linhas sísmicas. A superfície S1 erode o topo da unidade U1, resultando em forte truncamento erosivo, expresso por uma série de incisões canalizadas, que forma uma rede de paleodrenagem fluvial soterrada sob o preenchimento sedimentar da baía de Sepetiba (Figuras 3 e 4).

A atenuação do sinal sísmico e a presença

recorrente de reflexões múltiplas de horizontes de subfundo dificultaram a identificação da superfície-base da unidade sísmica U1. Contudo, onde reconhecível, a unidade é constituída pela fácies sísmicas $\boldsymbol{f} \mathbf{1}$ (Tabela 1), caracterizada por refletores subparalelos contínuos a descontínuos, contendo por vezes, algumas canalizações, sendo sismicamente interpretada como indicativa de um paleoambiente estuarino na região (Tabela 1 ).

As unidades sísmicas U2, U3 e U4, que se seguem, apresentam semelhanças entre si, por serem todas constituídas em sua maior parte por fácies sísmicas cuja característica principal é a ocorrência de refletores plano-paralelos a ondulados, contínuos a descontínuos, intercalados com múltiplas feições canalizadas (fácies f2c, Tabela 1). Contudo, as unidades U2, U3 e U4 apresentam diferenças nas características e dimensões das feições canalizadas, representando ambientes fluvio-estuarinos energeticamente diferenciados (Figura 3).

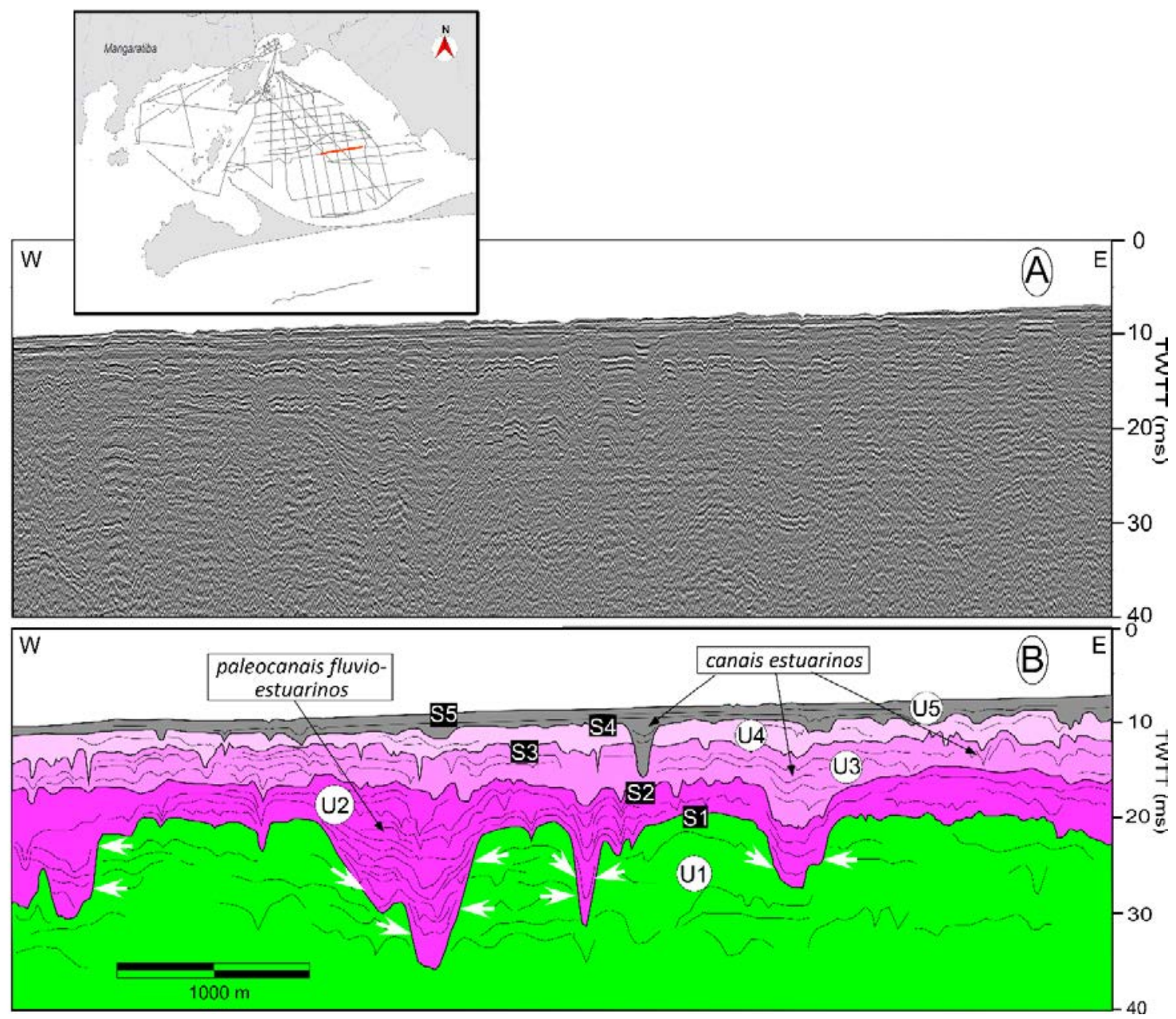

Figura 3. A - Perfil sísmico de alta resolução (Boomer $100 \mathrm{~J}$ ) de orientação "strike”, situado no interior da Baía de Sepetiba. B- Esquema interpretativo da linha sísmica com as unidades sísmicas identificadas U1-U5, separadas por suas superfícies limitantes. As setas brancas em B indicam truncamentos erosivos. TWTT (unidade convencional para "tempo duplo de percurso do sinal acústico”). 
Tabela 1. Fácies sísmicas características das unidades U1 a U5, definidas a partir de Sismoestratigrafia (e.g., Mitchum et al., 1977) e de estudos de caso de paleoambientes estuarinos (e,g., Chaumillon et al., 2010; Seminack \& Buynevich, 2013; Ho Bae et al., 2018).

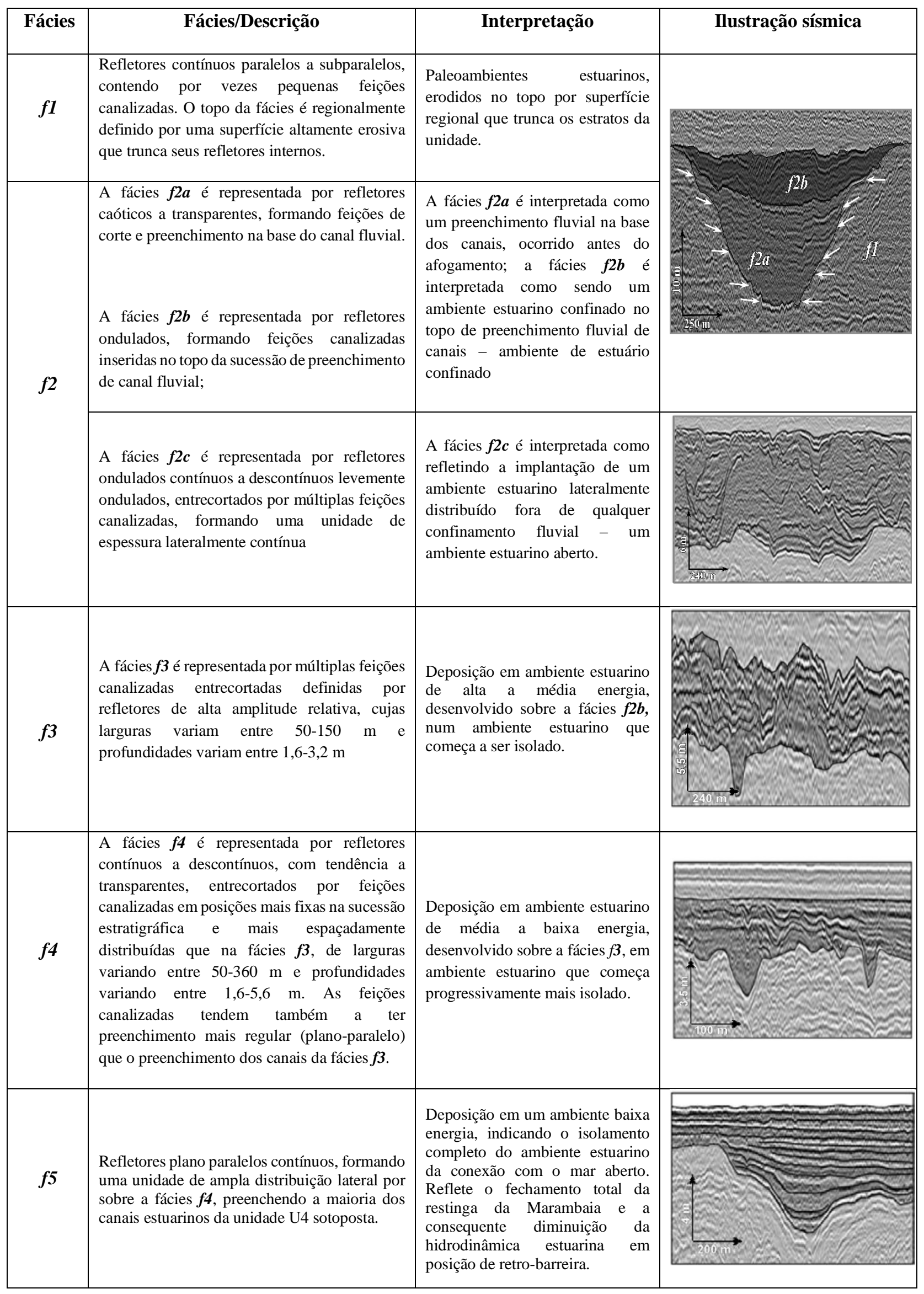



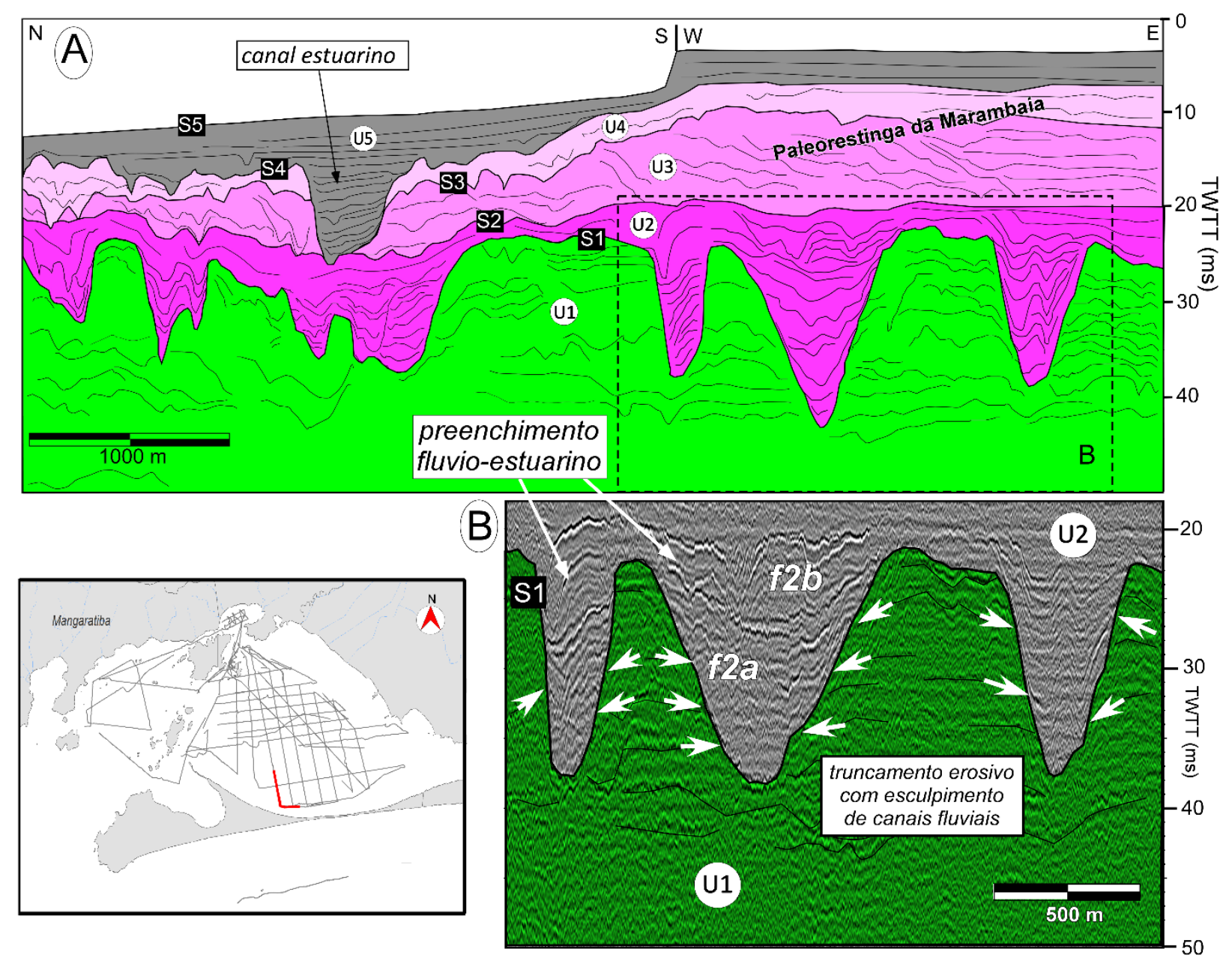

Figura 4. A- Esquema interpretativo das unidades sísmicas U1-U5 identificadas na baía d Sepetiba, separadas por suas superfícies limitantes (S1-S4). B- Zoom do perfil sísmico de alta resolução (fonte boomer $100 \mathrm{~J}$ ) ilustrando a ocorrência de paleocanais fluviais no interior da Baía de Sepetiba. As setas brancas em B indicam truncamentos erosivos. TWTT (unidade convencional para “tempo duplo de percurso do sinal acústico”).

\section{Unidade sísmica U2}

A unidade U2 é aquela que apresenta o maior número de fácies sísmicas internas. Paleocanais esculpidos sobre a superfície S1, são preenchidos na base pela fácies sísmicas $\mathbf{f} 2 \boldsymbol{a}$, interpretada como uma deposição de preenchimento de canal fluvial de alta energia hidráulica, ou seja, um ambiente tipicamente fluvial continental (Tabela 1; Figura 5). Já o topo do preenchimento do canal é caracterizado pela fácies $\boldsymbol{f} \mathbf{2} \boldsymbol{b}$, interpretada como sendo um preenchimento estuarino ainda confinado ao canal fluvial, indicando o início do afogamento marinho da paleodrenagem - um típico ambiente de estuário alongado (Tabela 1; Figura 5). Para o seu topo, a unidade U2 é caracterizada por toda sua extensão pela fácies f2c, interpretada como sendo um ambiente estuarino lateralmente distribuído, ou seja, fora do confinamento dos canais fluvial - um ambiente estuarino aberto produto de uma incursão marinha que afora toda a região, inclusive aquelas dos vales fluviais (Tabela 1; Figura 6).
A unidade U2 possui continuidade lateral em toda a região, e apresenta espessura sedimentar variando entre $2 \mathrm{~m}$ e $22 \mathrm{~m}$; as maiores espessuras correspondem às regiões de preenchimento de canais fluvio-estuarinos (Figura 5).

\section{Unidades sísmicas U3 e U4}

A unidade sísmica U3 é limitada pela superfície S2 em sua base, e pela superfície S3 em seu topo. Já a unidade sísmica U4 é limitada pela superfície S3 em sua base, enquanto seu topo é limitado pela superfície S4. Essas superfícies-topo S3 e S4 têm como principal característica a sua irregularidade, apresentando muitas incisões canalizadas (Figura 4).

Em termos de fácies sísmicas, as unidades U3 e U4 apresentam semelhanças mas também diferenças: (i) ambas as unidades são caracterizadas pela predominância de refletores internos subparalelos a ondulados, descontínuos e/ou caóticos, de alta amplitude, com a presença de múltiplas feições canalizadas de pequenas dimensões, interpretadas como canais de ambiente estuarino (Tabela 1; Figura 3); (ii) mas 

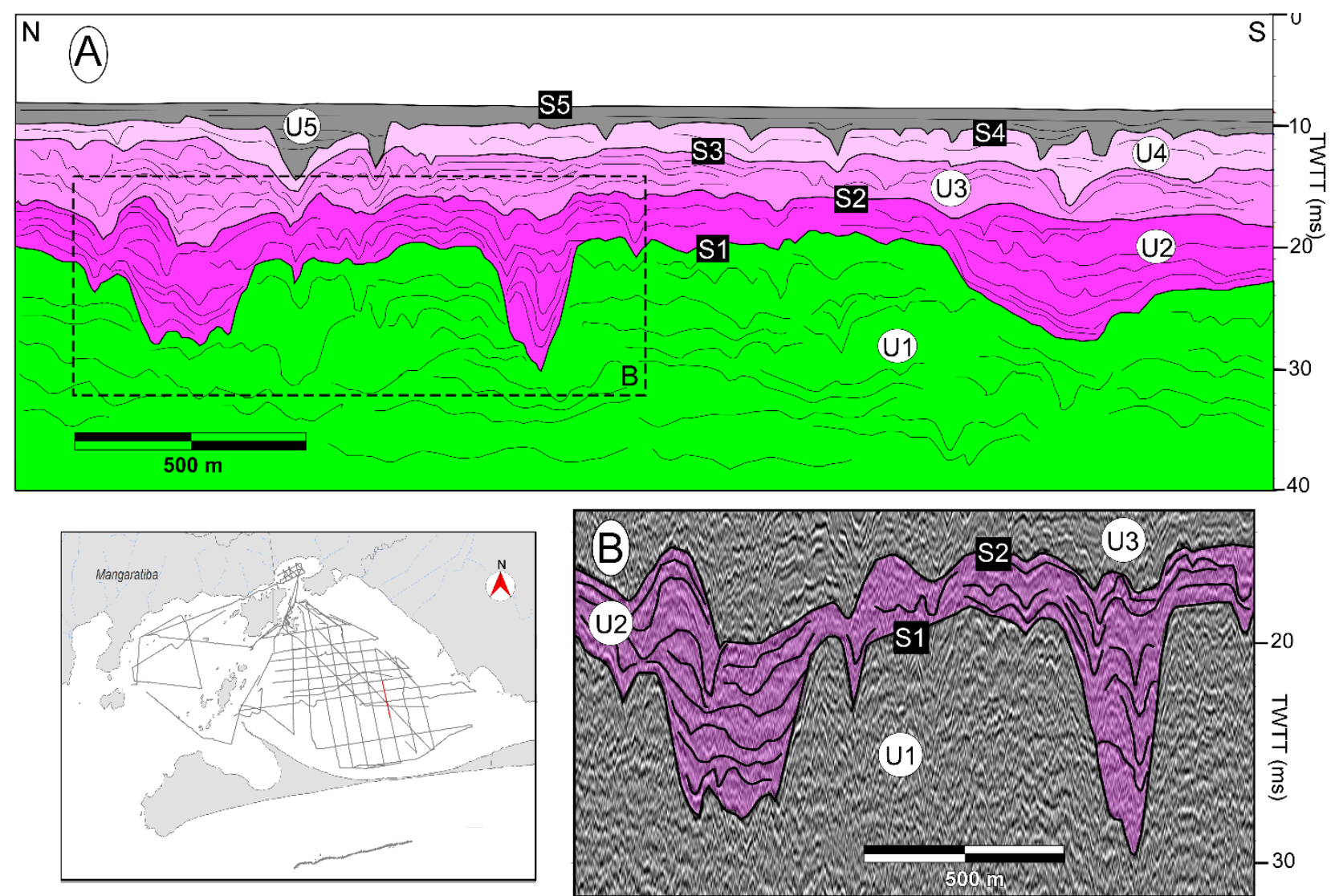

Figura 5. A- Esquema interpretativo das unidades sísmicas U1-U5 identificadas na baía d Sepetiba, separadas por suas superfícies limitantes (S1-S4). B- Zoom do perfil sísmico de alta resolução (fonte boomer $100 \mathrm{~J}$ ) ilustrando a fácies sísmica caraterística da unidade U2. TWTT (unidade convencional para “tempo duplo de percurso do sinal acústico”).
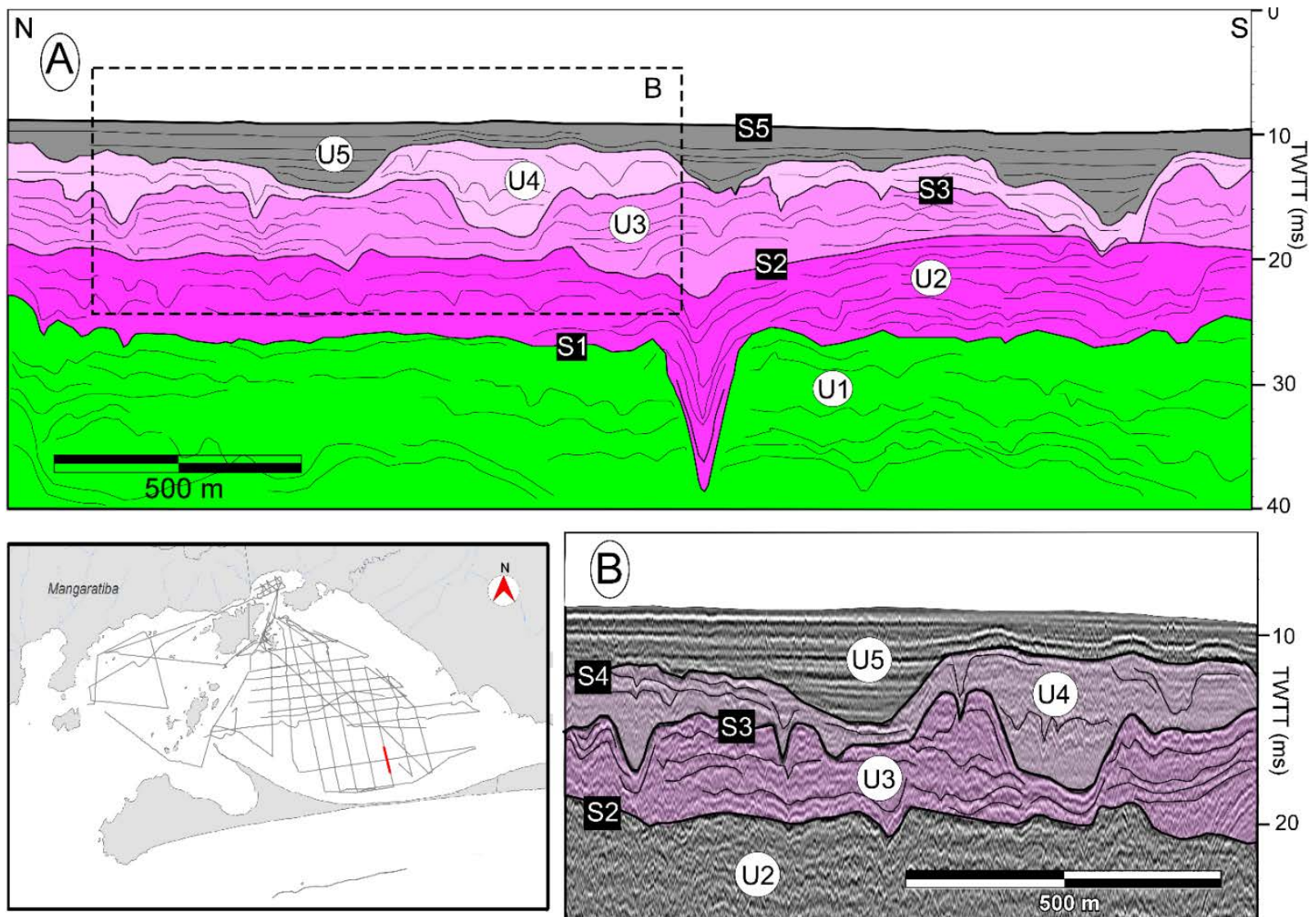

Figura 6. A- Esquema interpretativo das unidades sísmicas U1-U5 identificadas na baía de Sepetiba, separadas por suas superfícies limitantes (S1-S4). B. Zoom de perfil sísmico de alta resolução (Boomer $100 \mathrm{~J}$ ) ilustrando a ocorrência de paleocanais estuarinos nas unidades sísmicas U3 e U4. TWTT (unidade convencional para "tempo duplo de percurso do sinal acústico”). 
a unidade U4 tende a apresentar maiores feições canalizadas (Tabela 1), que também mantêm suas posições mais fixas na sucessão estratigráfica, sendo ainda mais espaçadamente distribuídas que as feições canalizadas da unidade U3 (respectivamente as fácies $\mathbf{f 4}$ e fácies $\mathbf{f 3}$; Tabela 1; Figura 6); e, (iii) as feições canalizadas da unidade U4 tendem também a ter preenchimento mais calmo (tendência a preenchimento planoparalelo indicado pela fácies $\mathbf{f 3}$; Tabela 1) que o preenchimento dos canais da unidade U3 (fácies f3; Tabela 1). Segundo tais características sismoestratigráficas, as diferenças de fácies sísmicas internas das unidades U3 e U4 foram interpretadas como representando uma diminuição gradativa da dinâmica estuarina da área, revelando a implantação de ambientes estuarinos progressivamente menos energéticos $\mathrm{e}$ mais isolados.

Em conjunto, as unidades U3 e U4 e apresentam espessura sedimentar variando entre $\sim 3-6 \mathrm{~m}$; as maiores espessuras correspondem às regiões de preenchimento de canais estuarinos (Figura 6).

\section{Unidade sísmica U5}

A unidade U5 representa a unidade topo da sucessão estratigráfica definida na área de estudo, sendo depositada sobre a superfície S4. A superfície S4 também se apresenta localmente esculpida por canais, contudo de maior dimensão (Tabela 1; Figuras 3, 4A, 5A e 6A).

Os dados sísmicos permitem também observar notáveis variações entre as fácies sísmicas da unidade U5 em relação às fácies que caracterizam as unidades U2-U4 descritas acima. A unidade U5 é caracterizada pela fácies f5, constituída essencialmente de refletores plano paralelos contínuos, formando uma unidade deposicional de preenchimento por sobre a fácies f4 (Tabela 1; Figuras 4A, 5A e 6A). Tais características de fácies sísmica permitem a interpretação da unidade U5 como a de um ambiente deposicional substancialmente mais calmo, representando deposição de sedimentos finos em ambiente estuarino de baixa energia, colmatando canalizações isoladas esculpidas sobre a superfície limite da unidade U4 sotoposta, levando assim à inativação de grande parte dos canais estuarinos anteriormente implantados (Figuras 4A, 5A e 6A).

A unidade U5 exibe uma espessura sedimentar média que varia entre cerca de $4-5 \mathrm{~m}$, espessando-se apenas nas regiões em que preenche canais isolados, onde pode atingir até $\sim 15$ m de espessura (Figura 4A).

\section{DISCUSSÃO}

Significado cronoestratigráfico da superfície S1

O cruzamento da base de dados sísmicos do presente trabalho com os dados sísmicos e informações de idade (datação ${ }^{14} \mathrm{C}$ AMS; Poço, 2015) de um horizonte sísmico da plataforma externa fluminense, revelou que:

(1) a superfície erosiva S1 identificada no presente estudo corresponde estratigraficamente à superficie S5 de Poço (2015), datada em 19,88 ka na região de plataforma externa. Tal superfície corresponde à expressão da última exposição subaérea da plataforma continental e região costeira fluminense (Superfície de Regressão Máxima - MRS), desenvolvida entre os estágios isotópicos marinhos MIS5e-MIS2 (Figura 2) e MRS (Figuras 7 e 8);

(2) a unidade U1, que tem a superfície-topo S1, corresponde assim à deposição sedimentar prédeglaciação, desenvolvida durante o penúltimo ciclo global de transgressão e de ótimo climático ocorrido entre MIS6-MIS5e ( 140- 126 ka; Figuras 2 e 8), estratigraficamente correlacionável à sequência Sq4 na plataforma continental (Maia et al., 2010; Reis et al., 2013); e,
(3) a rede de paleodrenagem fluvial esculpida sobre a superfície S1 na região da baía de Sepetiba representa o registro estratigráfico da acentuada queda do nível de base (da ordem de $130 \mathrm{~m}$ ) ocorrida durante a regressão marinha entre os estágios isotópicos MIS5e-MIS2 (regressão marinha de 100 ka de duração ocorrida entre 126- 20 ka), que expos a unidade transgressiva U1 anteriormente depositada (Figuras 2 e 8).

\section{Modelo glacio-eustático de deposição das unidades sísmicas U2-U5}

Como discutido acima, a superfície-topo da unidade sísmica U1 - a superfície S1, representa o registro do último período de exposição quase total da plataforma continental e região da atual baía de Sepetiba desenvolvido até o estágio isotópico marinho MIS2 ( 20ka). Logo, as unidades sísmicas U2 a U5, depositadas acima da superfície S1 - a superfície de regressão máxima (MRS), correspondem à deposição sedimentar ocorrida em decorrência do afogamento da área promovido pela última transgressão marinha na região (iniciada globalmente há 20ka; Figura 8). 

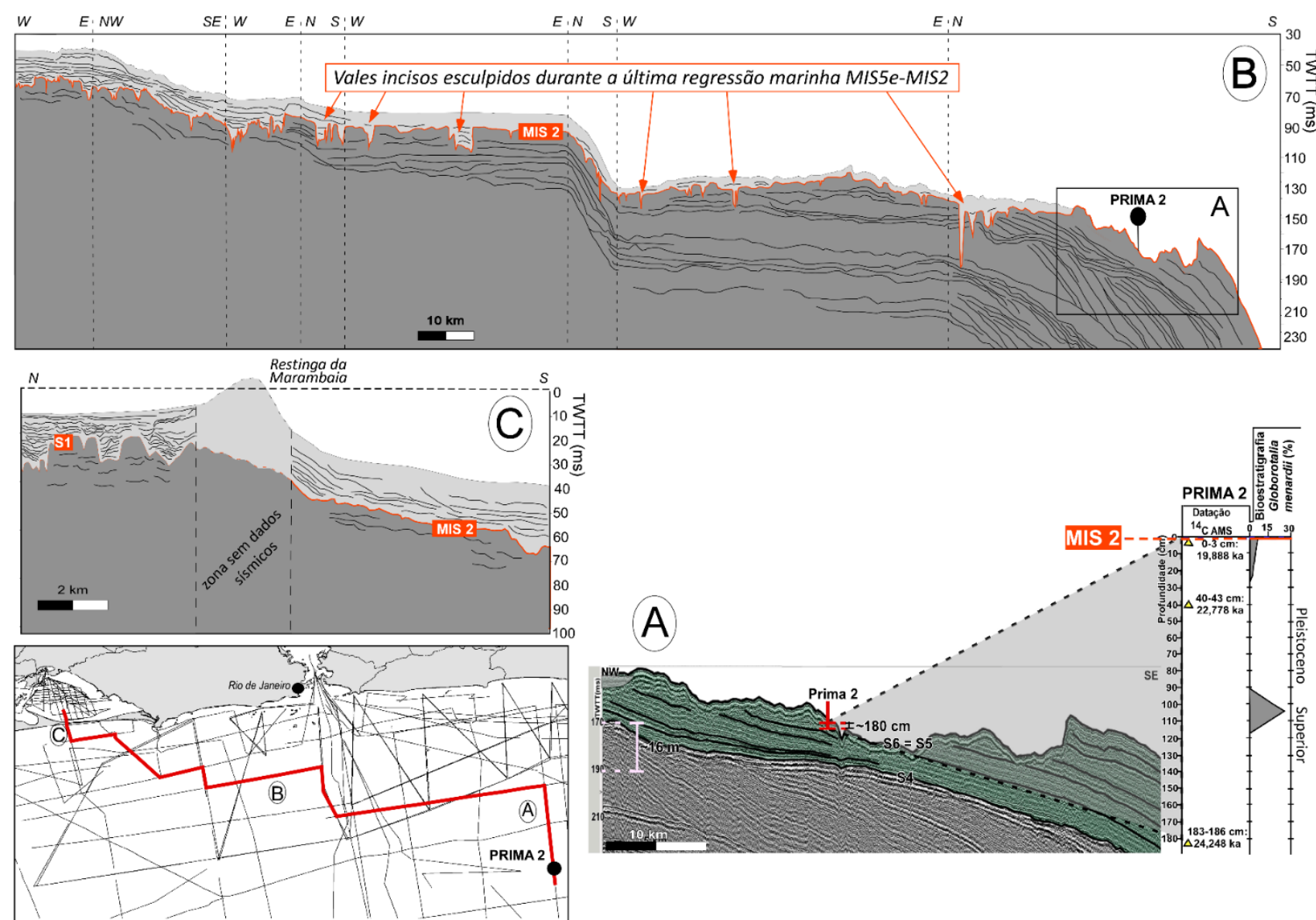

Figura 7. Em A - Linha sísmica e localização do testemunho PRIMA 2 na plataforma continental à frente do trecho entre a baía de Guanabara e Cabo Frio (Poço, 2015). Em B-Trajeto de cruzamento entre a posição da superfície MIS 2 (datada em PRIMA 2) e sua correlação com a superfície S1 interpretada na base de dados sísmicos do presente trabalho (em C). TWTT (unidade convencional para "tempo duplo de percurso do sinal acústico").

\section{Assim:}

(1) as unidades sísmicas U2-U5 correspondem às unidades deposicionais transgressivas e de mar alto (Catuneanu, 2006) que testemunham a inundação progressiva da plataforma continental e da região costeira fluminense durante a última deglaciação (Figura 8);

(2) nesse sentido, a sucessão estratigráfica U2-

U5 compõe uma sequência deposicional ainda em construção (sensu Hunt \& Tucker, 1992), composta apenas por unidades deposicionais transgressivas e de mar alto; e,

(3) o mapa de isópacas totais das unidades U2U5 revela ainda que a sedimentação pós-último glacial na região da baía de Sepetiba atinge espessuras consideráveis de até 30 m (Figura 9), substancialmente mais espessa que a espessura média de $5 \mathrm{~m}$ antes apontada por Borges (1998).

Nesse contexto, pode-se propor um modelo glacio-eustático de deposição de cada uma das unidades sísmicas U2 a U5, baseado na correlação entre: (i) o significado cronoestratigráfico da superfície S1 (Figura 8); (ii) as características das fácies sísmicas internas das unidades U2-U5 (Tabela 1); (iii) o traçado de curvas glacio-eustáticas extraídas da literatura (e.g., Bard et al., 1990; Angulo et al., 2006; Figura 10); e (iv) as diferentes fases de construção da restinga da Marambaia como reveladas por Dadalto (2017).

\section{Unidade U2}

Como mostrado anteriormente, a unidade sísmica U2 é caracterizada por vales incisos com preenchimento fluvial na base e fluvio-estuarino confinado no topo dos canais (fácies $\mathbf{f} \mathbf{2} \boldsymbol{a}$ e $\boldsymbol{f} \mathbf{2} \boldsymbol{b}$; Tabela 1), recobertos finalmente por fácies estuarinas de alta energia amplamente distribuídas na área de estudos (fácies $f 2 c$; Tabela 1). Além disso, a correlação com os resultados de estudos anteriores na região da restinga da Marambaia evidencia que a deposição da unidade U2 ocorreu antes do início da construção da paleorrestinga da Marambaia (Fase II de Dadalto, 2017; Figura 8). Deste modo, pode-se afirmar que a unidade U2 foi depositada durante a transgressão marinha na região, em um ambiente deposicional que passa de fluvial (continental) na base, para um ambiente estuarino confinado no topo dos canais fluviais, e finalmente para um ambiente estuarino aberto, 


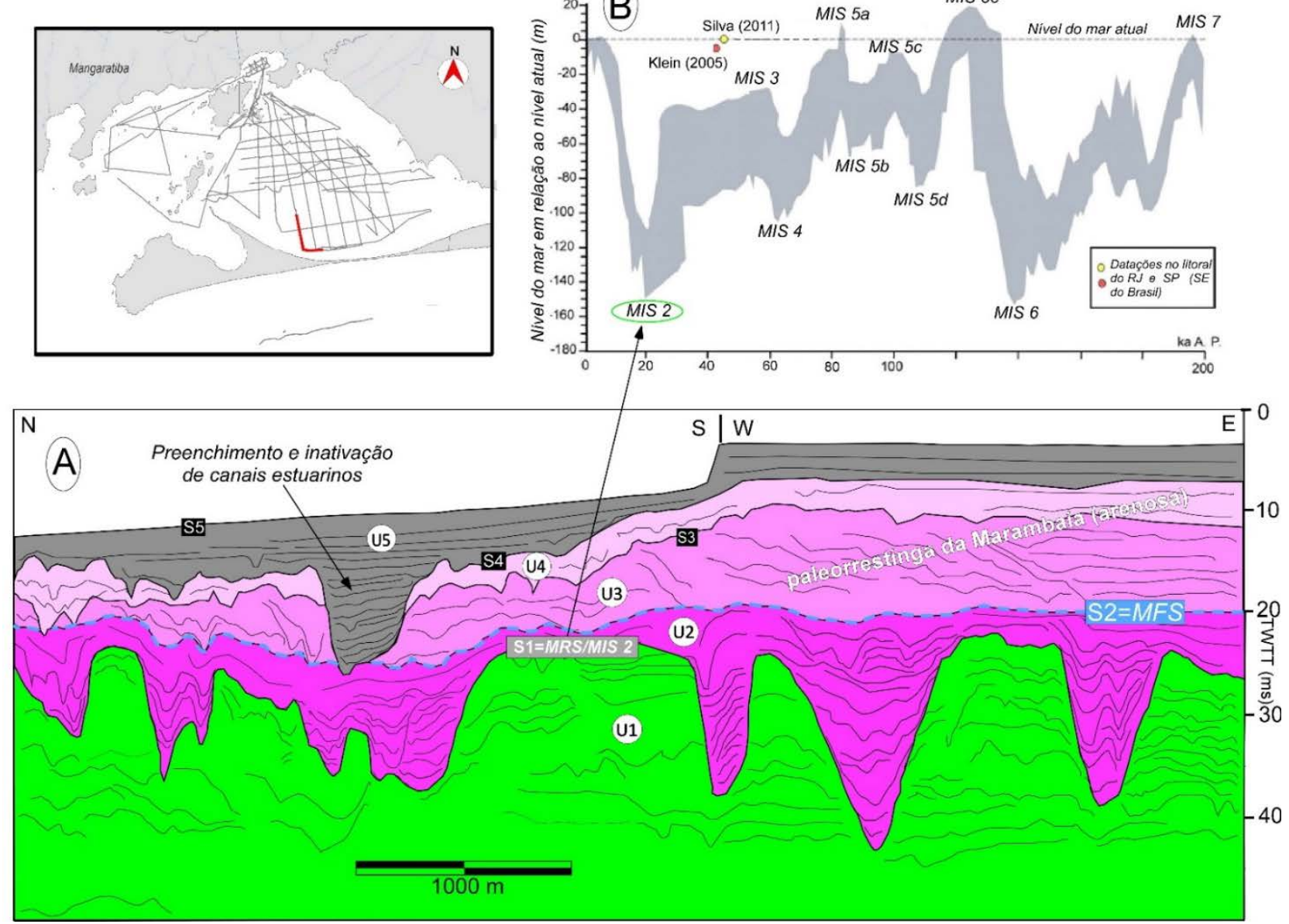

Figura 8. A- Perfil sísmico localizado no interior da baía de Sepetiba, ilustrando as unidades sísmicas U1-U5 e as superfícies limitantes S1- S4, que as separam e, em destaque, a correlação da superfície S1 com o estágio isotópico marinho MIS2 e sua interpretação como superfície MRS. B- Envelope de curvas eustáticas do Pleistoceno SuperiorHoloceno compiladas por Rabineau et al. (2006), modificado por Friederichs et al. (2013). MIS=Marine Isotope Stage; MFS= Superfície de Inundação Máxima; MRS= Superfície de regressão máxima. TWTT (unidade convencional para “tempo duplo de percurso do sinal acústico”).

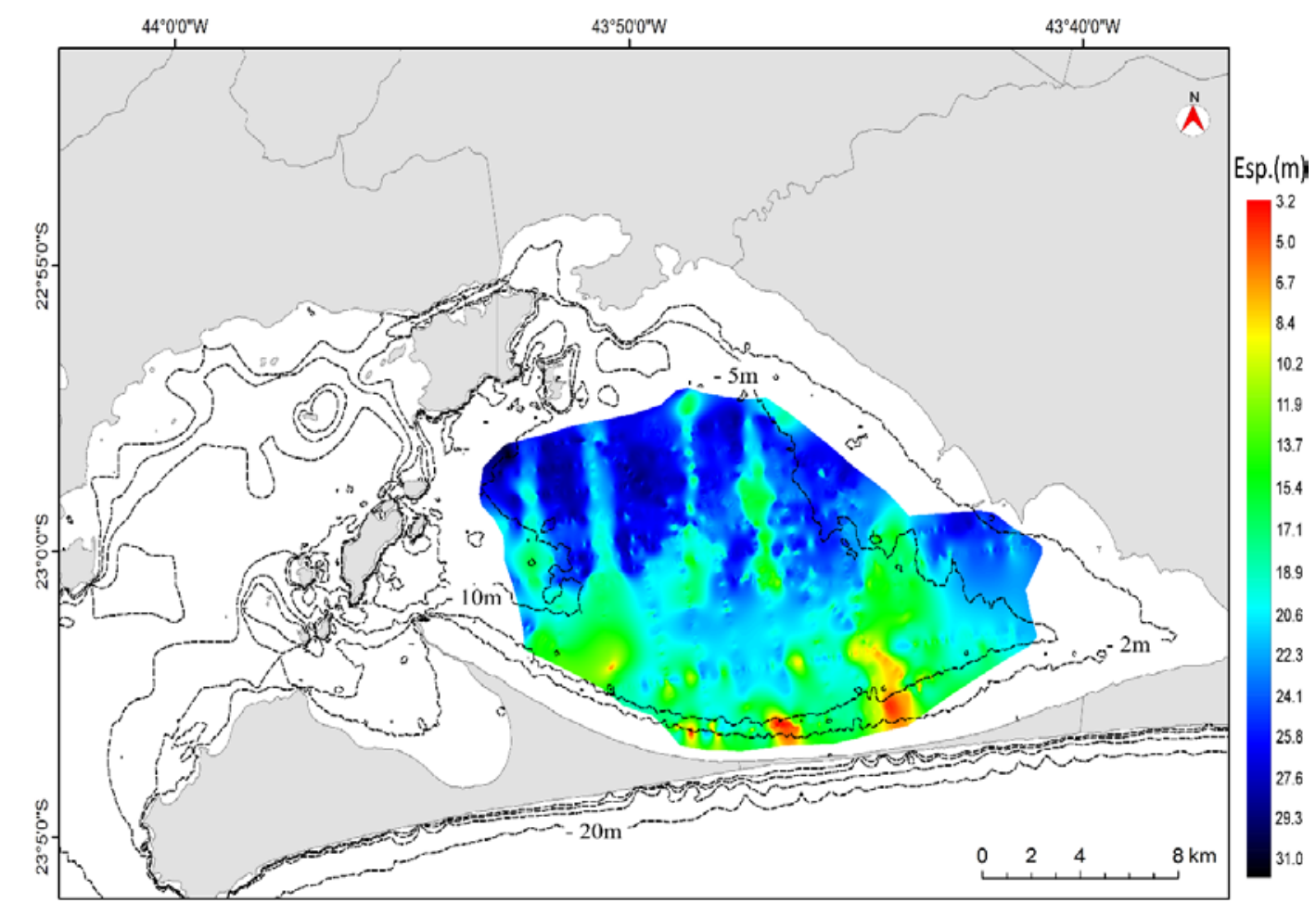

Figura 9. Mapa de isópacas totais das unidades sísmicas U2-U5 ilustrando a espessura da sedimentação pós-último máximo glacial (unidades U2-U5) que preenche a região hoje ocupada pela baía de Sepetiba. 


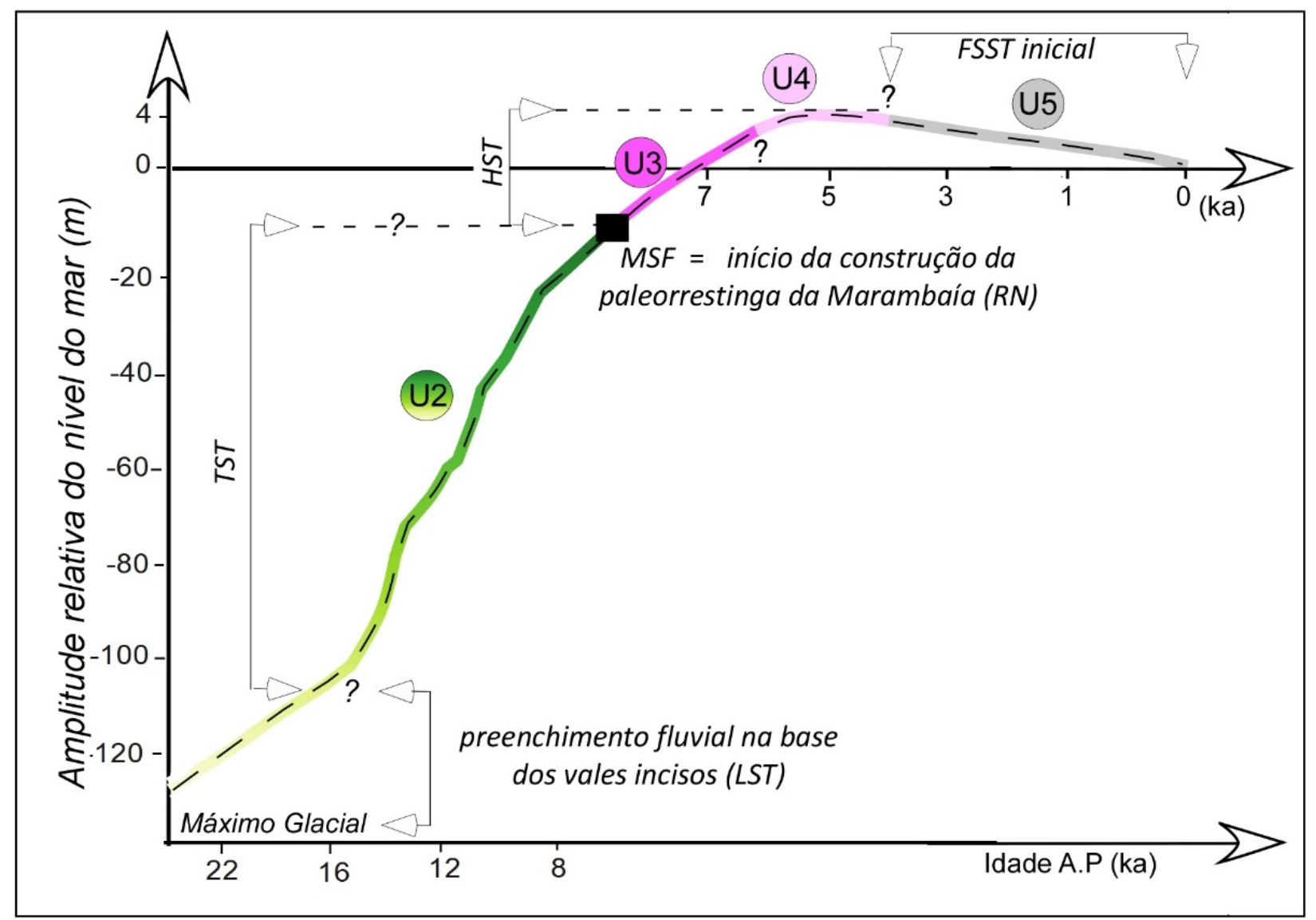

Figura 10. Curva composta simplificada de variação do nível do mar para os últimos 22 ka (deglaciação Pleistoceno Tardio-Holoceno). A curva de posição de nível do mar para os últimos 7 ka (acima do atual) é baseada em dados da curva eustática proposta por Angulo et al. (2006) para o litoral sudeste brasileiro. A curva para posições de nível do mar abaixo do atual é baseada em medições de isótopos estáveis em corais na região de Barbados, proposta por Bard et al. (1990). MSF= Superfície de Inundação Máxima. LST= Trato de Sistema de Mar Baixo; TST=; Trato de Sistema Transgressivo; HST=Trato de Sistema de Mar Alto; FSST inicial= início de implantação do Trato de Sistema de Regressão Forçada.

de alta energia, em conexão direta com o oceano aberto, ou seja, sem a existência de uma restinga isolando o sistema. Vale ressaltar que por questões de simplificação, o preenchimento fluvial na base dos vales incisos foi incluído na unidade U2. Formalmente, a parte basal desse preenchimento é a resposta do sistema fluvial à queda do nível de base que se estabiliza no máximo glacial e também corresponde ao início da transgressão marinha, mas quando ainda impera depósitos de progradação normal em região de borda de plataforma. Desse modo, os depósitos de fundo de vales incisos compõem ainda o trato de sistema de mar baixo (Figura 10). A parte superior do preenchimento fluvial já corresponde ao segmento glacioeustático da transgressão que já ocorre a taxas mais elevadas, contudo antes que a região costeira seja afogada. Dito isso, o ambiente estuarino aberto indicado pela ocorrência da fácies sísmica $\mathbf{f} \boldsymbol{c}$ em direção ao topo da unidade U2 (Tabela 1 e Figura 6A) aponta para um modelo paleogeográfico de ambiente estuarino em conexão direta com o mar aberto. Uma enseada sem nenhum confinamento é compatível com a implantação de um ambiente estuarino em afogamento, desenvolvido até a fase de construção da paleorrestinga, já apontada por Dadalto (2017) como tendo se iniciado por sobre a superfície de inundação máxima na região (Maximum Flooding Surface-MFS), que define assim o limite superior do trato de sistema transgressivo (TST) na região (Figuras 8 e 10).

\section{Unidades U3 e U4}

As fácies sísmicas que compõem as unidades U3 e U4 (fácies $\mathbf{f} 3$ e $\mathbf{f 4}$, Tabela 1), marcadas por canais de maré que se tornam gradativamente mais espaçados e mais fixos no espaço, apontam para um cenário de diminuição progressiva de circulação hidrodinâmica em relação ao estuário do tipo aberto implantado durante a deposição da unidade U2 anterior (Figuras 8 e 10).

A diminuição progressiva de circulação hidrodinâmica na região da baía, indicada pelas fácies sísmicas das unidades U3 e U4, revela um 
período de crescente isolamento do ambiente estuarino, associado às fases de deposição da paleorrestinga da Marambaia (Figura 8): (i) a construção da paleorrestinga (o corpo arenoso U2+U3 hoje soterrado) ocorre como feição progradante sobre a Superfície MSF (Dadalto, 2017) representada no presente trabalho pela superfície S2 (Figura 8); e (ii) as características sísmicas e de perfis de Radar de Penetração no Solo (GPR; Dadalto, 2017) indicam que a deposição da paleorrestinga ocorreu em condições de regressão normal (RN), com idade inicial desconhecida, mas que provavelmente ocorreu a partir de $\sim 8$-10 ka (Dadalto, 2017), induzida pela tendência de desaceleração da curva de elevação eustática (Figura 10). Nesse contexto, as características das fácies sísmicas estuarinas das unidades U3 e U4 podem ser assim explicadas: (i) a deposição dessas unidades ocorreu temporalmente associada à progradação da paleorrestinga da Marambaia, desenvolvida em condições de regressão normal entre a superfície $M F S$ e o início da regressão marinha na região (Dadalto. 2017; Superfície S4 no presente trabalho, Figura 10); (ii) desse modo a deposição dessas unidades constitui um Trato de Sistema de Mar Alto na região (Catuneanu, 2006), implantado ainda durante o afogamento do estuário, ou seja, durante o período de transgressão marinha com tendência de taxas de elevação eustática em desaceleração (Figura
10); (iii) as condições de energia hidrodinâmica progressivamente menor dentro da baía durante deposição de U3 e U4 ocorrem em resposta ao crescimento da paleorrestinga, que é acompanhado do fechamento progressivo dos canais de maré que a cortavam (Dadalto, 2017), resultando num crescente isolamento dos ambientes estuarinos do mar aberto, localizados em uma posição de retro-barreira (Figura 8).

\section{Unidade U5}

Finalmente, a unidade U5 é caracterizada em toda a região da baía de Sepetiba por deposição estuarina mais calma, representada por refletores plano-paralelos contínuos, formando depósitos amplamente distribuídos por toda a baía (fácies $\mathbf{5 5}$; Tabela 1; Figura 6). Localmente, esta unidade preenche canais de circulação que se tornam inativos. Por tais características, a unidade U5 é interpretada como um ambiente estuarino depositado durante e após o fechamento por completo da restinga da Marambaia, que teria provocado uma mudança significativa nas condições ambientais: (i) inativação dos canais de circulação, típicos de ambientes fechados; e (ii) preenchimento de tais canais por sedimentos mais finos (Figura 8). A unidade U5 é temporalmente correlacionável a fase de desenvolvimento da atual da restinga emersa da Marambaia, ocorrido em contexto de regressão forçada (Dadalto, 2017; Figuras 8 e 10), e que hoje se encontra elevada acima do nível do mar (Figura 7C).

\section{CONCLUSÕES}

A análise das fácies e unidades sísmicas interpretadas no interior da atual baía de Sepetiba revelou importantes informações tanto de ambientes deposicionais como paleogeográficas, que apontam para modificações ambientais sofridas pela região da atual baía de Sepetiba durante a última transgressão marinha Pleistoceno Tardio-Holoceno (últimos 20 ka). As principais conclusões podem ser assim resumidas:

(i) a última regressão marinha ocorrida entre os estágios isotópicos marinhos MIS5e-MIS2 esculpiu uma rede de drenagem, composta por vales fluviais hoje fossilizados sob a cobertura sedimentar composta pelas unidades U2-U5;

(ii) a fácies sísmica que compõe o preenchimento do topo dos paleocanais fluviais da unidade U2 atesta a preservação no registro sismoestratigráfico de típicos estuários alongados, desenvolvidos durante a fase inicial do afogamento marinho da paleodrenagem;

(iii) as características sísmicas das unidades U2-U5 indicam que o ambiente estuarino hoje representado pela baía de Sepetiba evoluiu, da base para o topo, de um ambiente estuarino aberto de alta energia, em forma de enseada diretamente conectada ao mar (deposição da Unidade U2), para um ambiente progressivamente mais isolado e de energia hidrodinâmica paulatinamente descrente (deposição das Unidades U3 e U4), influenciados pelas fases de construção, e progressivo fechamento dos canais de maré da restinga da Marambaia. Finalmente, um ambiente estuarino similar ao atual (deposição da Unidade U5), isolado por extensa restinga contínua, começou a se desenvolver durante a regressão marinha pósnível mais elevado ( 5,8 ka A.P.). 


\section{AGRADECIMENTOS}

Os autores agradecem pelo apoio financeiro concedido para a realização deste trabalho: à FAPERJ (Edital PENSA RIO, E-26/010.003024/2014; Edital Cooperação Internacional FAPERJ-Sorbonne Université, E-26/210.821/2015; Edital CIENTISTA DO NOSSO ESTADO, E-26/202.958/2016); ao CNPq (Edital CNPq Universal, Proc. 474358/2013-5), e à CAPES (Edital CIÊNCIAS DO MAR, 23038.051609/2009-61). Agradecemos ainda à CAPES pela concessão de bolsa de mestrado e doutorado, respectivamente, a Guilherme Amendola e a Tatiana Pinheiro Dadalto. Agradecimento também ao CNPq pela concessão de bolsas de pesquisa a A.T. dos Reis, Cleverson G. Silva e Virgínia Martins. Nosso agradecimento ao apoio da empresa IHS Kingdom pela concessão de licenças educacionais do programa de interpretação sísmica SMT Kingdom Suite®. Esta é uma contribuição do Grupo de Pesquisa GEOMARGEM - Geologia e Oceanografia de Margens Continentais Passivas.

\section{REFERÊNCIAS}

ANGULO, R.J.; LESSA, G.C.; SOUZA, M.C.S. A critical review of mid-Late Holocene sea-level fluctuations on the eastern Brazilian coastline. Quaternary Science Reviews, v. 25, n. 56, p. 486-506, 2006.

BARD, E.; HAMELIN, B.; FAIRBANKS, R.G. U-Th ages obtained by mass spectrometry in corals from Barbados: sea level during the past 130,000 years. Nature, v. 346, p. 456-458, 1990.

BORGES, H.V. (1998). Geological Evolution of Sepetiba Bay and Marambaia Barrier Island, Brazil. New York, 1998. 145p. Tese (Doutorado) - University of New York -SUNY

CATUNEANU, O. (2006). Principles of Sequence Stratigraphy, Elsevier, 375p., 2006.

CHAUMILLON, E.; TESSIER; B.; REYNAUD, J-Y Stratigraphic records and variability of incised valleys and estuaries along French coasts. Bulletin de la Société Géologique de France, v. 181, n. 2, p.75-85, 2010.

DADALTO, T. Arquitetura Estratigráfica e Evolução Geológica da Restinga da Marambaia (RJ). Niterói, 2017. 275 p. Tese (Doutorado em Geologia e Geofísica Marinha) Universidade Federal Fluminense.

FRIEDERICHS, Y.L.; REIS, A.T.; SILVA, C.G.; TOULEMONDE, B.; GUERRA, J.V. Arquitetura Sísmica do Sistema Fluvio-estuarino da Baía de Sepetiba Preservado na Estratigrafia Rasa da Plataforma Interna Adjacente, Rio de Janeiro. Brazilian Journal of Geology, v. 43, n. 1, p. 124-138, 2013.

HO BAE, S.; KONG, G.S.; LEE, G.S.; YOO, D.G.; KIM, D.C. Incised channel morphology and depositional fill of the paleoSeomjin River in the continental shelf of the South Sea, Korea. Quaternary International, v. 468, p. 49-61, 2018.

HUNT, D. \& TUCKER, M.E. Stranded parasequences and the forced regressive wedge systems tract: deposition during baselevel fall. Sedimentary Geology, v. 81, p. 1-9, 1992.

MAIA, R.M.C.; REIS, A.T.; ALVES, E.C.; SILVA, C.G.; SILVA, A.; GUERRA, J.V.; GORINI, C.; GORINI, C.; SILVA, A.; ARANTES-OLIVEIRA, R. Architecture and stratigraphic framework of shelf sedimentary systems off Rio de Janeiro state, northern Santos basin-Brazil. Brazilian Journal of Oceanography, v. 58, p. 15-29, 2010.
MITCHUM J.R., R.M.; VAIL, P.R.; SANGREE, J.B. Seismic Stratigraphy and Global Changes of Sea Level, Part 6: Stratigraphy Interpretation of Seismic Reflection Patterns in Deposicional Sequences. In: Seismic Stratigraphy Applications to Hydrocarbon Exploration, v. 26. Tulsa, AAPG, p. 294-312, 1977.

POÇO, R.G.T.C. (2015). Estratigrafia sísmica e paleodrenagem de sistemas deposicionais quaternários da plataforma sul fluminense, Bacia de Santos. Niterói, 2015. 272 p. Dissertação (Mestrado em Dinâmica dos Oceanos e da Terra) - Universidade Federal Fluminense

RABINEAU, M.; BERNÉ, S.; OLIVET, J.L.; ASLANIAN, D.; JOSEPH, P. Paleo sea levels reconsidered from direct observation of paleoshoreline position during Glacial Maxima (for the last 500,000 yr). Earth and Planetary Science Letters, v. 252, p. 119-137, 2006.

REIS, A.T.; MAIA, R.M.C.; SILVA, C.G.; RABINEAU, M.; GUERRA, J.V.; GORINI, C.; AYRES, A.; ARANTESOLIVEIRA, R.; BENABDELLOUAHED M., SIMÕES, I.; TARDIN, R. Origin of step-like and lobate seafloor features along the continental shelf off Rio de Janeiro State, Santos basin-Brazil. Geomorphology, v. 203, n. 1, p. 20-45, 2013.

SEMINACK, C.T. \& BUYNEVICH, I.V. Sedimentological and geophysical signatures of a relict tidal inlet complex along a wave-dominated barrier: Assateague island, Maryland, U.S.A. Journal of Sedimentary Research, v. 83, p. 132-144, 2013.

ZALÁN, P.V. \& OLIVEIRA, J.A.B. Origem e evolução estrutural do Sistema de Riftes Cenozóicos do Sudeste do Brasil. Boletim de Geociências da Petrobras, v. 13, n. 2, p. 269-300, 2005. 